\title{
Investigations of Different Phases Responsible for Changes in Optical Properties of Organic Semiconducting Device Material Thin Films
}

\author{
Vivek Kumar Shukla ${ }^{1}$ and Jaya Maitra ${ }^{2}$ \\ ${ }^{1}$ Department of Applied Physics, School of Vocational Studies and Applied Sciences, Gautam Buddha University, \\ Greater Noida, Gautam Budh Nagar 201312, India \\ ${ }^{2}$ Department of Applied Chemistry, School of Vocational Studies and Applied Sciences, Gautam Buddha University, \\ Greater Noida, Gautam Budh Nagar 201312, India \\ Correspondence should be addressed to Vivek Kumar Shukla; vkshuk@gmail.com
}

Received 22 November 2012; Revised 6 February 2013; Accepted 12 February 2013

Academic Editor: Sung-Hoon Kim

Copyright (C) 2013 V. K. Shukla and J. Maitra. This is an open access article distributed under the Creative Commons Attribution License, which permits unrestricted use, distribution, and reproduction in any medium, provided the original work is properly cited.

The environment sensitivity of organic semiconductors may change their molecular structure and hence optical properties. Exploiting this concept, experiments were performed on a green light emitting material bis(8-hydroxy quinoline)Zinc, (Znq ${ }_{2}$ ) used in organic light emitting diodes (OLEDs). Thin films were deposited at varying deposition parameters, and their properties were compared. We investigated that as deposited films have a significant component of $\mathrm{Znq}_{2}$ tetramer out of two known forms, that is, dihydrate and anhydrous tetramer $\left(\mathrm{Znq}_{2}\right)_{4}$, the films deposited at lower deposition rates have higher anhydrous content. The degradation of thin film is shown, that changes the optical properties of film from green emission to blue which may be due to water adsorption and crystallization.

\section{Introduction}

Small molecules such as metal based quinoline derivatives like Tris-(8-hydroxyquinoline) aluminum $\left(\mathrm{Alq}_{3}\right)$ have been shown to have high efficiency as well as stability in organic light emitting devices, OLEDs [1]. Potential of Zinc(II) bis(8hydroxyquinoline) $\left(\mathrm{Znq}_{2}\right)$ has been amply recognized in the literature [2-5]. $\mathrm{Znq}_{2}$ devices have shown advantages over $\mathrm{Alq}_{3}$ in electron transport and have higher quantum yields in device performance which results in lower operating voltages [2]. Further, the devices have been shown to be comparatively more stable under influence of high operating voltages [35]. It is shown that electroluminescence (EL) of $\mathrm{Znq}_{2}$ devices does not shift with operating voltage [2]. As $\mathrm{Znq}_{2}$ is a symmetric molecule, it does not have variegated isomers as found in tris-quinalato structures [6]. Thermal analysis of $\mathrm{Znq}_{2}$ powders by differential scanning calorimetry (DSC) demonstrates a sole oligomeric species and no polymorphism [7]. It has also been shown that thermal stability of zinc complexes is higher than other transport layers [8]. In order to take advantage of various properties of this molecule, it is important to understand and correlate its properties in powders with thin films. While the lack of polymorphism is an important attribute in device application, the structure of the molecules in thin film forms is poorly understood. However, no clear study has yet been done on morphology and properties of $\mathrm{Znq}_{2}$ as thin film. In solution or powder form $\mathrm{Znq}_{2}$ is known to exist as monomer with $\mathrm{H}_{2} \mathrm{O}$ group attached to it. It has been shown that oligomers, in particular, tetramer of $\mathrm{Znq}_{2}$, are energetically favorable as well in solid state $[7,9]$. Though many reports have suggested that tetramers may be present in thin films and may be responsible for lower operating voltages of $\mathrm{Znq}_{2}$ devices, it is not very clear with what geometry $\mathrm{Znq}_{2}$ molecules arrange themselves in as thin films $[7,10]$. A lack of understanding of molecular arrangement in thin film forms further complicates the applicability of substituted bis-quinolates [11]. In this work, we aim to understand the structural transformation and changes in optical properties 
of $\mathrm{Znq}_{2}$ thin films deposited at varying deposition parameters and compare them with those of powdered $\mathrm{Znq}_{2}$.

\section{Experiments}

$\left(\mathrm{Znq}_{2}\right) \cdot 2 \mathrm{H}_{2} \mathrm{O}$ and $\left(\mathrm{Znq}_{2}\right)_{4}$ were synthesized in the laboratory [5]. The composition of the precipitate was $\mathrm{Znq}_{2} \cdot 2 \mathrm{H}_{2} \mathrm{O}$ as ascertained by X-ray experiments. In order to obtain $\left(\mathrm{Znq}_{2}\right)_{4}$ crystals, the precipitate was sublimed at $\sim 200^{\circ} \mathrm{C}$.

Thin films of $\mathrm{Znq}_{2}$ were deposited on glass and polished Si substrates in ultra-high vacuum system $\left(\sim 10^{-8}\right.$ mbar $)$ with multiple thermal evaporation sources. The crucible temperature was varied from $290^{\circ} \mathrm{C}$ to $350^{\circ} \mathrm{C}$ for a series of samples which were deposited from $0.1 \AA$ /s to $10 \AA /$ s. Film thickness was kept at $\sim 100 \mathrm{~nm}$.

$\mathrm{X}$-ray and FTIR studies were conducted in order to probe structural order of the films. Grazing angle X-ray measurements were taken at incident angle of $0.5^{\circ}$ and $4^{\circ}$, and $2 \Theta$ were scanned from $2^{\circ}$ to $40^{\circ}$ using $\mathrm{CuK} \alpha$ radiation with a wavelength of $1.541 \AA$. Photoluminescence data at room temperature was recorded using a spectrofluorometer (Fluorolog 3, Jobin Yvon) with front face detecting geometry, in which the emitted signal is collected at $22^{\circ}$ with respect to the normal at the surface of the sample, coincident with the excitation light direction. Thermal analysis of the organic samples was carried out using thermal analyzer (Model TG/DTA 6300, SII NanoTechnology Inc., Japan).

\section{Results and Discussion}

3.1. $\mathrm{Znq}_{2}$ : Powder Form. X-ray diffraction data on $\mathrm{Znq}_{2}$ samples before $\left(\mathrm{Znq}_{2} \cdot 2 \mathrm{H}_{2} \mathrm{O}\right)$ and after sublimation are shown in Figure 1. The upper XRD pattern shows a signature peak at $6.96^{\circ}$, which is of $\mathrm{Znq}_{2} \cdot 2 \mathrm{H}_{2} \mathrm{O}$. The lower XRD pattern can be readily identified as $\left(\mathrm{Znq}_{2}\right)_{4}$ [12].

Figure 2 shows FTIR spectra of $\mathrm{Znq}_{2} \cdot 2 \mathrm{H}_{2} \mathrm{O}$ and $\left(\mathrm{Znq}_{2}\right)_{4}$. The high-frequency region lying between 3600 and $1700 \mathrm{~cm}^{-1}$ contains absorption bands mainly originating from localized hydrogen stretching vibrations. The middle region from 1700 to $1000 \mathrm{~cm}^{-1}$ relates to heavy atom in-plane stretching and bending vibrations. The last part of the spectrum comprising of the frequency region shows the out-of-plane and torsional modes [13].

Comparison of FTIR spectra of two phases shows a variation in characteristic spectral parameters. Broad band at $3100-3500 \mathrm{~cm}^{-1}$ attributed to stretch in $\mathrm{OH}$ bond is present in $\left(\mathrm{Znq}_{2}\right) \cdot 2 \mathrm{H}_{2} \mathrm{O}$ while it is missing in $\left(\mathrm{Znq}_{2}\right)_{4}$. The intensity ratio of $3333 \mathrm{~cm}^{-1}$ band to $1110 \mathrm{~cm}^{-1}$ band, commonly used to study the water molecule number in metal-quinoline chelates, yields ratio of 0.7. This ratio is slightly higher than expected value (0.6) due to minor residual water content in the sample [14]. Peaks at 602 and $650 \mathrm{~cm}^{-1}$ are quite pronounced in $\left(\mathrm{Znq}_{2}\right)_{4}$ indicating higher in-plane ring distortion. The vibrations at 1606, 1577, 1500, 1467, 1388, and $1327 \mathrm{~cm}^{-1}$ were allocated to the quinoline group of $\mathrm{Znq}_{2}$. The bands at 1500 and $1468 \mathrm{~cm}^{-1}$ should correspond to both the pyridyl and phenyl groups in $\mathrm{Znq}_{2}$.

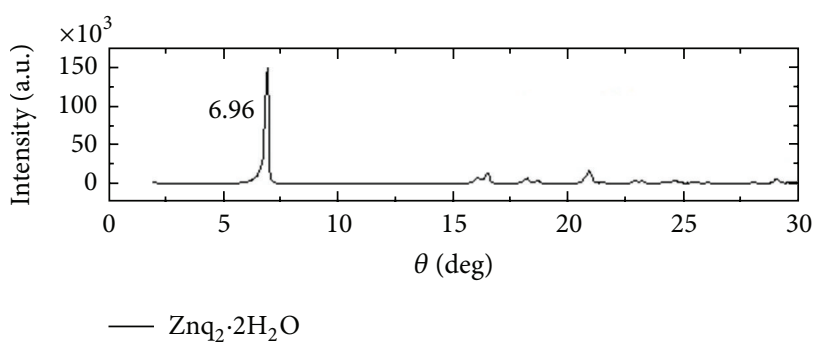

(a)

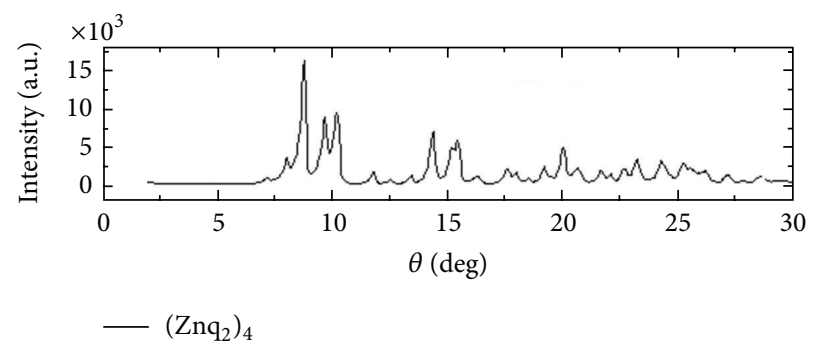

(b)

FIgURE 1: X-ray diffraction data on $\mathrm{Znq}_{2}$ samples before $\left(\mathrm{Znq}_{2} \cdot 2 \mathrm{H}_{2} \mathrm{O}\right)$ and after sublimation $\left(\left(\mathrm{Znq}_{2}\right)_{4}\right)$.

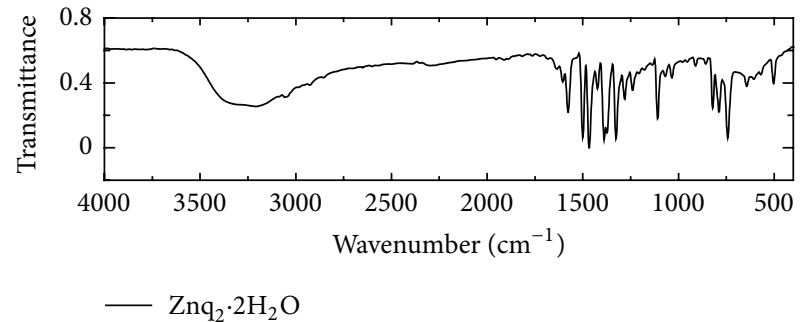

(a)

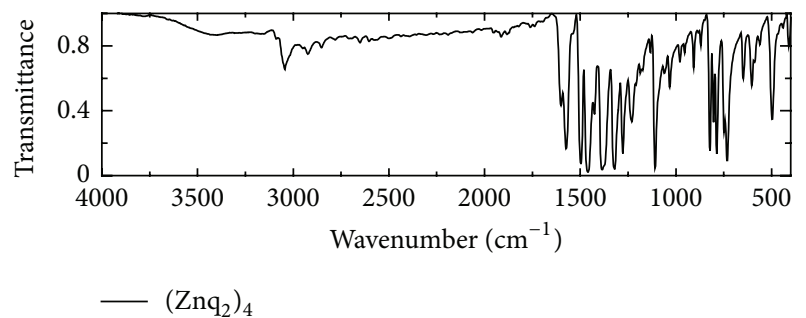

(b)

FIGURE 2: FTIR spectra of $\left(\mathrm{Znq}_{2}\right) \cdot 2 \mathrm{H}_{2} \mathrm{O}$ and $\left(\mathrm{Znq}_{2}\right)_{4}$ powders. Note that the broad peak at $3400 \mathrm{~cm}^{-1}$ characteristic of $\mathrm{OH}$ stretching is missing in $\left(\mathrm{Znq}_{2}\right)_{4}$.

Figure 3 shows DTA and TGA results. First weight loss starts from $110^{\circ} \mathrm{C}$ in $\mathrm{Znq}_{2} \cdot 2 \mathrm{H}_{2} \mathrm{O}$, due to loss of water, and can be observed as endothermic peak at $122^{\circ} \mathrm{C}$ in DTA as well. Presence of minor peak at the same temperature in $\left(\mathrm{Znq}_{2}\right)_{4}$ may be due to atmospheric moisture as such a peak is not observed in $\left(\mathrm{Znq}_{2}\right)_{4}$ [2]. An additional exothermic peak for $\mathrm{Znq}_{2} \cdot 2 \mathrm{H}_{2} \mathrm{O}$ is shown at $199^{\circ} \mathrm{C}$. This peak may be due to release of energy by fusion of anhydrous $\mathrm{Znq}_{2}$ molecules into oligomers. Next strong endothermic peak occurs at $357^{\circ} \mathrm{C}$ followed by decomposition at $440^{\circ} \mathrm{C}$. The sublimation temperature of $\mathrm{Znq}_{2}$ is $357^{\circ} \mathrm{C}$. 


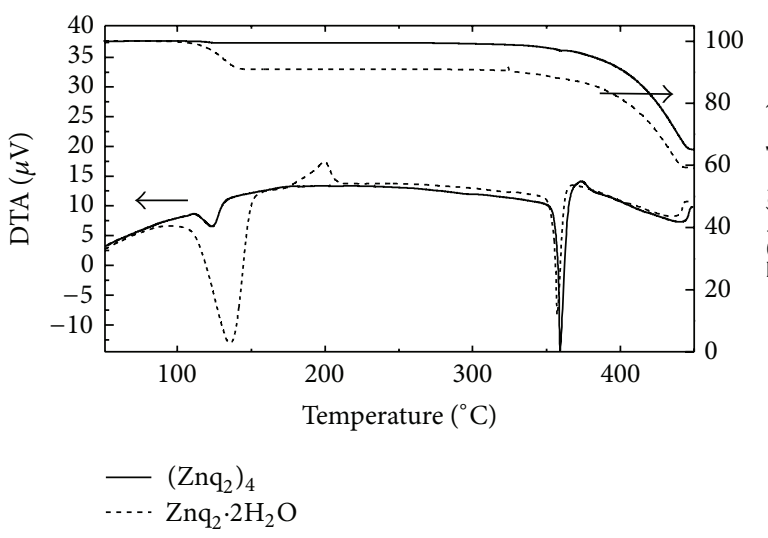

Figure 3: Thermal Analysis of $\left(\mathrm{Znq}_{2}\right) \cdot 2 \mathrm{H}_{2} \mathrm{O}$ and $\left(\mathrm{Znq}_{2}\right)_{4}$.

Figure 4 shows photoluminescence (PL) emission spectrum of these two samples. PL spectrum of $\left(\mathrm{Znq}_{2}\right)_{4}$ shows peak at $542 \mathrm{~nm}$ whereas PL spectrum of $\mathrm{Znq}_{2} \cdot 2 \mathrm{H}_{2} \mathrm{O}$ shows PL peak at $506 \mathrm{~nm}$. This indicates that HOMO-LUMO gap in $\left(\mathrm{Znq}_{2}\right) \cdot 2 \mathrm{H}_{2} \mathrm{O}$ is broader. Possibly, fusion of $\mathrm{Znq}_{2}$ into its oligomers leads to decrease in HOMO-LUMO gap due to improved $\pi-\pi$ stacking.

It is interesting to note that molecular structure of $\mathrm{Znq}_{2}$ changes appreciably in its various forms. The water molecules are loosely attached to zinc atom and are easily removed by heating the compound to $135^{\circ} \mathrm{C}$ [15].

Anhydrous $\mathrm{Znq}_{2}$ is amorphous in nature and tends to form tetramer at temperatures slightly higher than $135^{\circ} \mathrm{C}$ [12]. In order to form the tetramer, two anhydrous zinc quinolate molecules get connected by two bridging oxygen atoms to form an asymmetric unit. Two asymmetric units related by a center of symmetry, connected by two bridging oxygen atoms, make the whole molecule tetrameric.

Another pathway for obtaining tetrameric structure is combination of monomer and trimer [7]. The structure of $\left(\mathrm{Znq}_{2}\right)_{4}$ contains four zinc atoms, two of which are in the center and two on the edges.

The structure around zinc atoms at the edge is that of distorted trigonal bipyramid, and the zinc atoms lie in pentacoordinate geometry whereas the central atoms are hexacoordinate. $\left(\mathrm{Znq}_{2}\right)_{4}$ is a highly symmetric almost planar molecule with several inversion symmetry points. The presence of this symmetry forces the $\left(\mathrm{Znq}_{2}\right)_{4}$ molecules to arrange bridging terminal ligands in parallel fashion adjacent to tetrameric units, resulting in a close intermolecular $\pi-\pi$ interaction [2]

3.2. $\mathrm{Znq}_{2}$ : Thin Films. A series of thin films of $\mathrm{Znq}_{2}$ were deposited on different glass and $\mathrm{Si}$ substrates with deposition rate as a variable. Details of the films are given in Table 1. Because of the fact that polymers [16], organic small molecules like $\mathrm{Znq}_{2}$ [17-22], and other organometallic complexes [23] are environment sensitive, a set of thin films deposited at variable deposition rates were exposed to environment in order to understand possible degradation and structural transformation mechanisms in $\mathrm{Znq}_{2}$.

Figure 5 shows $\mathrm{X}$-ray spectrum of pristine and environmentally exposed thin films of $\mathrm{Znq}_{2}$. The fresh films show

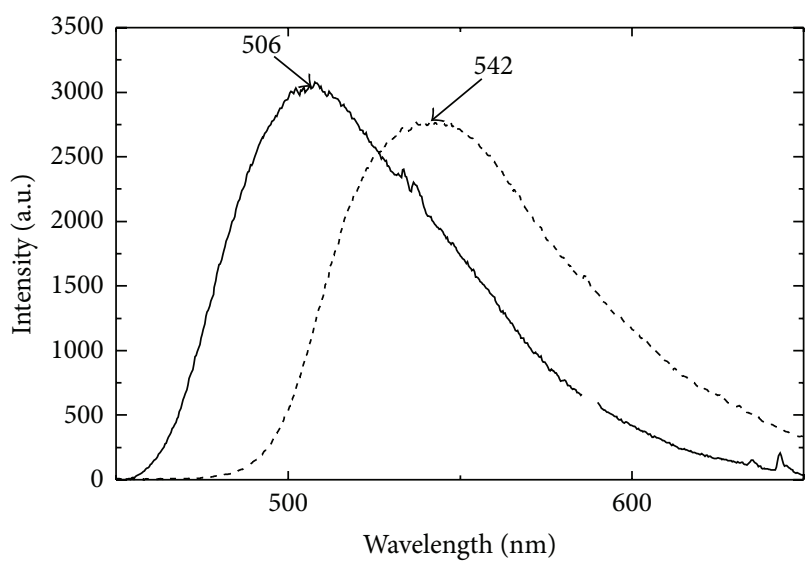

$$
-\mathrm{Znq}_{2} \cdot 2 \mathrm{H}_{2} \mathrm{O}
$$

FIGURE 4: Photoluminescence spectrum of $\mathrm{Znq}_{2}$ powders.

TABLE 1: Details of $\mathrm{Znq}_{2}$ powders and thin films. Note that the powder may be at lower temperature than temperature of crucible made of ceramic

\begin{tabular}{lccc}
\hline Sample name & Sample form & $\begin{array}{c}\text { Deposition rate } \\
(\AA / \mathrm{s})\end{array}$ & $\begin{array}{c}\text { Crucible } \\
\text { Temp }\left({ }^{\circ} \mathrm{C}\right)\end{array}$ \\
\hline $\mathrm{Znq}_{2} \cdot 2 \mathrm{H}_{2} \mathrm{O}$ & Powder (as prepared) & - & - \\
$\left(\mathrm{Znq}_{2}\right)_{4}$ & Powder (sublimed) & - & - \\
$\mathrm{Zn0p2}$ & Thin film & 0.2 & 290 \\
$\mathrm{Zn0p5}$ & Thin film & 1 & 310 \\
$\mathrm{Zn1p0}$ & Thin film & 1.5 & 312 \\
$\mathrm{Zn} 2 \mathrm{p} 0$ & Thin film & 2 & 316 \\
$\mathrm{Zn} 2 \mathrm{p} 5$ & Thin film & 2.5 & 320 \\
$\mathrm{Zn5p0}$ & Thin film & 5 & 330 \\
$\mathrm{Zn10p0}$ & Thin film & 10 & 350 \\
\hline
\end{tabular}

a broad peak at $8.35^{\circ}$. The presence of this peak points to the fact that structurally the molecules have a $\left(\mathrm{Znq}_{2}\right)_{4}$ like composition in an amorphous structure. The exposed film shows the presence of an intense peak at 6.9 degrees, which is signature of $\mathrm{Znq}_{2} \cdot 2 \mathrm{H}_{2} \mathrm{O}$, and the absence of a broad peak at 8.35 degrees. This suggests that $\mathrm{H}_{2} \mathrm{O}$ molecule has now become attached to $\mathrm{Znq}_{2}$ leading to crystallization. This observation leads to conjecture that either there was a sizable fraction of anhydrous $\mathrm{Znq}_{2}$ or tetramer $\mathrm{Znq}_{2}$ has broken down in the thin film. The tetramer of $Z_{n q_{2}}$ has been reported to be a stable compound which does not degrade under exposure to environment [7]. If the films were composed of fully tetrameric component, it is unlikely that $\mathrm{H}_{2} \mathrm{O}$ molecule could get attached to the compound. Thus, we can conclude that there may be a large fraction of disordered phase.

Figure 6 shows FTIR spectra of thin films at different deposition rates (see Table 1). A comparison of thin films and powders (see Figure 2) shows that the molecular structure of all deposited films is close to tetrameric one; intensification and shifting of peak at $610 \mathrm{~cm}^{-1}$ indicating higher out of plane and torsional distortion. The broad band $3214 \mathrm{~cm}^{-1}$ 


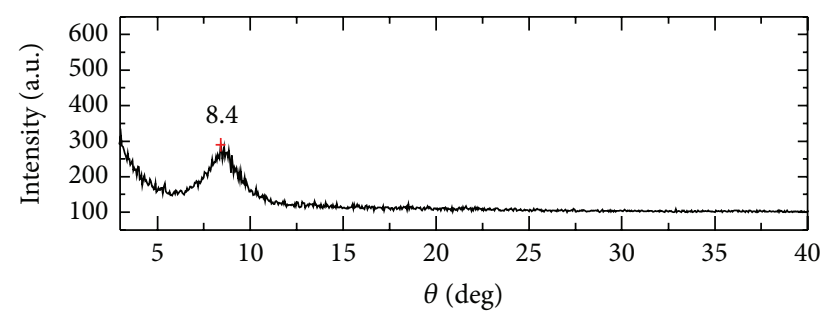

— As deposited film

(a)

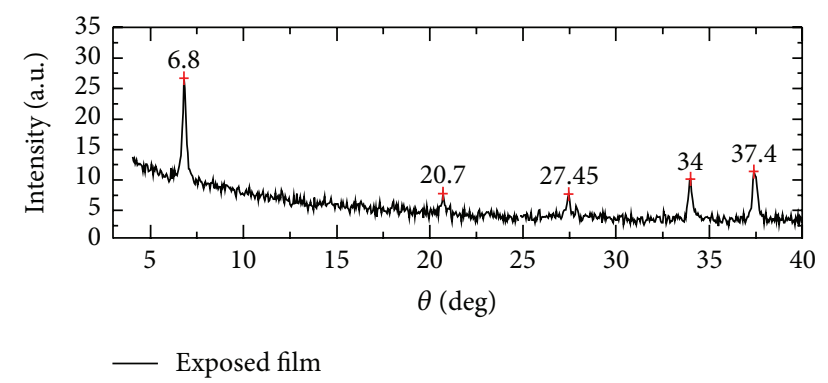

(b)

Figure 5: X-ray spectrum of a thin film of $\mathrm{Znq}_{2}$ deposited at $0.2 \AA / \mathrm{s}$ $(\mathrm{Zn} 0 \mathrm{p} 2)$ and the same film exposed to laboratory ambient for a week.

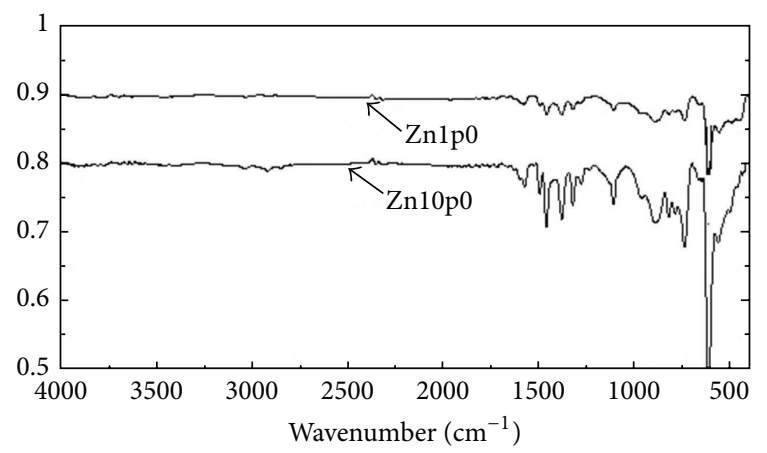

FIGURE 6: Infrared transmission spectra (in arbitrary unit) of two fresh $\mathrm{Znq}_{2}$ thin films on Si substrates deposited at the rate of $1 \AA / \mathrm{s}$ and $10 \AA /$ s (from top to bottom).

which is missing in pristine thin films is quite apparent in the environmentally exposed films (see Figure 7) again indicating that the thin films are not fully tetrameric.

Figure 7 shows FTIR spectra of the thin films exposed to atmosphere. Broad peak due to hydration which was not present in pristine films can be seen in these films. The ratio of $1100 \mathrm{~cm}^{-1}$ and $3300 \mathrm{~cm}^{-1}$ was used to characterize $\mathrm{Znq}_{2} \cdot 2 \mathrm{H}_{2} \mathrm{O}$ as material. This ratio is seen to be $\sim 0.1$ in thin films again indicating that pristine thin films must contain a fraction of anhydrous and amorphous $\mathrm{Znq}_{2}$.

We have also observed that films deposited at lower rates show antistokes shift in PL spectrum faster (2-4 weeks, laboratory ambient) than films deposited at higher rates with time. This suggests that tetrameric component has increased in the composition of thin films and the films are denser in

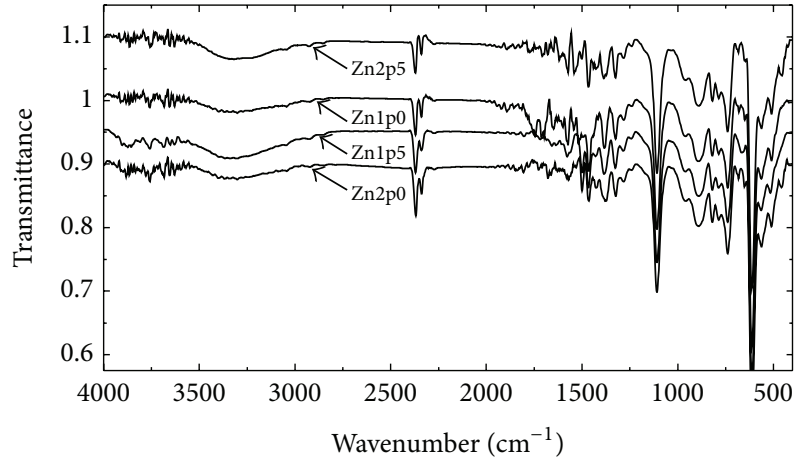

FIGURE 7: Infrared transmission spectra (in arbitrary unit) of environmentally exposed $\mathrm{Znq}_{2}$ thin films deposited at different rates of $1,1.5,2.0$, and $2.5 \AA / \mathrm{s}$.

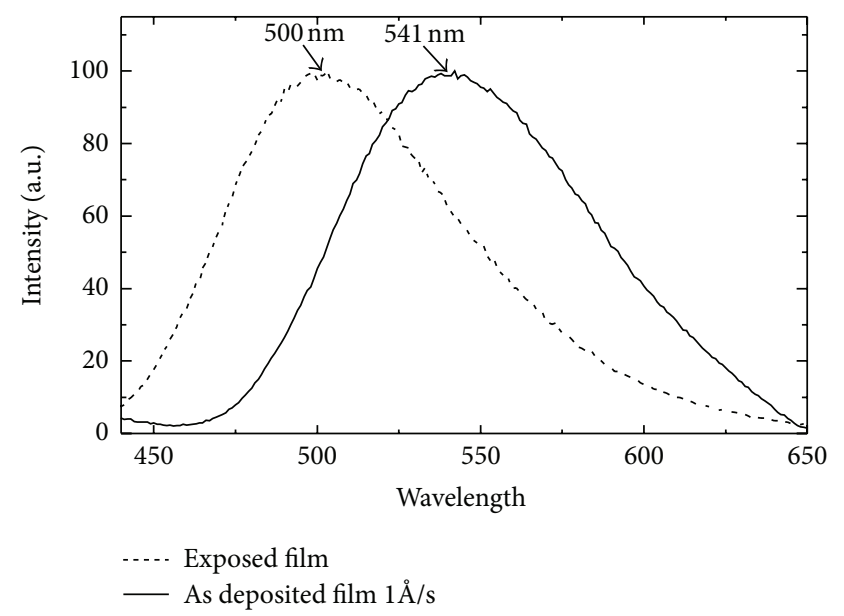

FIgURE 8: Photoluminescence peak shift from $540 \mathrm{~nm}$ in pristine thin film to $500 \mathrm{~nm}$ in environmentally exposed film deposited at $1 \AA ̊ / s$.

nature. The absorption spectrum also shows blue shift in the absorption band.

All the pristine films deposited at different rates show PL excitation at $375 \mathrm{~nm}$ and emission about $540 \mathrm{~nm}$. PL spectrum again suggests that pristine films contain tetramer as well as disordered component. PL spectrum can be fitted with two Gaussians suggesting two major levels in the band gap.

Figure 8 shows that environmental exposure results in blue shift ( $506 \mathrm{~nm}$ from $540 \mathrm{~nm}$ ) of the PL spectrum when exposed to air for extended period. Our results show that, whatever may be the starting compound for sublimation of $\mathrm{Znq}_{2}$, the thin films formed are of similar structure. As $\mathrm{Znq}_{2}$ sublimes at temperature around $350^{\circ} \mathrm{C}$, it is natural that conversion of $\mathrm{Znq}_{2}$ powders to its stable tetramer form has already taken place.

\section{Conclusions}

$\mathrm{Znq}_{2}$ comprising different isomeric phases was synthesized. Thin films of $\mathrm{Znq}_{2}$ were deposited as a function of deposition rate. X-ray diffraction data on $\mathrm{Znq}_{2}$ powders comprising 
different phases have been presented. The photoluminescence data corresponding to each phase have been clearly identified. As deposited thin films are shown to be amorphous in nature with a strong presence of $\left(\mathrm{Znq}_{2}\right)_{4}$. These films show a PL peak at $\sim 540 \mathrm{~nm}$. Exposure to oxygen environment leads to water adsorption and crystallization of thin films leading to a blue shift in the PL peak position. Films deposited at lower temperatures (lower rates) convert more quickly (approximately two weeks, laboratory ambient) to dihydrate $\mathrm{Znq}_{2}$. This suggests that $\left(\mathrm{Znq}_{2}\right)_{4}$ is present in higher density in films deposited at higher deposition rates.

\section{Acknowledgments}

Technical support from Samtel Center for Display Technologies, Indian Institute of Technology Kanpur, is gratefully acknowledged. Authors also thank Dr. Satyendra Kumar for useful discussions.

\section{References}

[1] A. Kimyonok, X. Y. Wang, and M. Weck, "Electroluminescent poly(quinoline)s and metalloquinolates," Polymer Reviews, vol. 46, no. 1, pp. 47-77, 2006.

[2] L. S. Sapochak, F. E. Benincasa, R. S. Schofield et al., "Electroluminescent zinc(II) bis(8-hydroxyquinoline): structural effects on electronic states and device performance," Journal of the American Chemical Society, vol. 124, no. 21, pp. 6119-6125, 2002.

[3] N. Du, Q. Mei, and M. Lu, "Quinolinate aluminum and zinc complexes with multi-methyl methacrylate end groups: synthesis, photoluminescence, and electroluminescence characterization," Synthetic Metals, vol. 149, no. 2-3, pp. 193-197, 2005.

[4] G. Giro, M. Cocchi, P. Di Marco et al., "Role played by cell configuration and layer preparation in LEDs based on hydroxyquinoline metal complexes and a triphenyl-diamine derivative (TPD)," Synthetic Metals, vol. 102, no. 1-3, pp. 1018-1019, 1999.

[5] Y. Hamada, T. Sano, M. Fujita, T. Fujii, Y. Nishio, and K. Shibata, "Organic electroluminescent devices with 8-hydroxyquinoline derivative-metal complexes as an emitter," Japanese Journal of Applied Physics, Part 2, vol. 32, no. 4, pp. L514-L515, 1993.

[6] Z.-A. Jian, Y.-Z. Luo, J.-M. Chung et al., "Effects of isomeric transformation on characteristics of $\mathrm{Alq}_{3}$ amorphous layers prepared by vacuum deposition at various substrate temperatures," Journal of Applied Physics, vol. 101, no. 12, Article ID 123708, 6 pages, 2007.

[7] L. S. Sapochak, A. Falkowitz, K. F. Ferris, S. Steinberg, and P. E. Burrows, "Supramolecular structures of zinc (II) (8-quinolinolato) chelates," Journal of Physical Chemistry B, vol. 108, no. 25, pp. 8558-8566, 2004.

[8] N. Donzé, P. Péchy, M. Grätzel, M. Schaer, and L. Zuppiroli, "Quinolinate zinc complexes as electron transporting layers in organic light-emitting diodes," Chemical Physics Letters, vol. 315, no. 5-6, pp. 405-410, 1999.

[9] Y. Kai, M. Moraita, N. Yasuka, and N. Kasai, "The crystal and molecular structure of anhydrous zinc 8-quinolinolate complex, $\left[\mathrm{Zn}(\mathrm{C} 9 \mathrm{H} 6 \mathrm{NO})_{2}\right]_{4}$," Bulletin of the Chemical Society of Japan, vol. 58, no. 6, pp. 1631-1635, 1985.

[10] M. Ghedini, M. La Deda, I. Aiello, and A. Grisolia, "Synthesis and photophysical characterisation of soluble photoluminescent metal complexes with substituted 8-hydroxyquinolines," Synthetic Metals, vol. 138, no. 1-2, pp. 189-192, 2003.
[11] T. A. Hopkins, K. Meerholz, S. Shaheen et al., "Substituted aluminum and zinc quinolates with blue-shifted absorbance/ luminescence bands: synthesis and spectroscopic, photoluminescence, and electroluminescence characterization," Chemistry of Materials, vol. 8, no. 2, pp. 344-351, 1996.

[12] B. S. Xu, Y. Y. Hao, H. Wang, H. F. Zhou, X. G. Liu, and M. W. Chen, "The effects of crystal structure on optical absorption/ photoluminescence of bis(8-hydroxyquinoline)zinc," Solid State Communications, vol. 136, no. 6, pp. 318-322, 2005.

[13] T. Gavrilko, R. Fedorovich, G. Dovbeshko et al., "FTIR spectroscopic and STM studies of vacuum deposited aluminium (III) 8-hydroxyquinoline thin films," Journal of Molecular Structure, vol. 704, no. 1-3, pp. 163-168, 2004.

[14] H. C. Pan, F. P. Liang, C. J. Mao, J. J. Zhu, and H. Y. Chen, "Highly luminescent zinc(II)-bis(8-hydroxyquinoline) complex nanorods: sonochemical synthesis, characterizations, and protein sensing," Journal of Physical Chemistry B, vol. 111, no. 20, pp. 5767-5772, 2007.

[15] S. Y. Oh, C. H. Lee, E. S. Jung, J. W. Choi, and P. J. Jung, "Characteristics of organic EL device using PDPMA and heat-treated 8hydroxyquinoline-zinc complex," Molecular Crystals and Liquid Crystals Science and Technology Section A, vol. 371, pp. 459-462, 2001.

[16] S. Kumar, A. K. Biswas, V. K. Shukla, A. Awasthi, R. S. Anand, and J. Narain, "Application of spectroscopic ellipsometry to probe the environmental and photo-oxidative degradation of poly(p-phenylenevinylene) (PPV)," Synthetic Metals, vol. 139, no. 3, pp. 751-753, 2003.

[17] S. Kumar, V. K. Shukla, and A. Tripathi, "Ellipsometric investigations on the light induced effects on tris(8-hydroxyquinoline) aluminum $\left(\mathrm{Alq}_{3}\right)$," Thin Solid Films, vol. 477, no. 1-2, pp. 240243, 2005.

[18] V. K. Shukla, S. Kumar, and D. Deva, "Light induced effects on the morphology and optical properties of tris-(8-hydroxyquinoline) aluminium $\left(\mathrm{Alq}_{3}\right)$ small molecular thin film," Synthetic Metals, vol. 156, no. 5-6, pp. 387-391, 2006.

[19] V. K. Shukla, S. Kumar, and D. Deva, "AFM studies on formation of new phase responsible for enhanced photoluminescence in light-emitting small molecular thin films," Journal of Luminescence, vol. 121, no. 1, pp. 132-136, 2006.

[20] V. K. Shukla and S. Kumar, "Study of optical properties and light induced effects on Inq 3 thin film used in organic light emitting devices," Optical Materials, vol. 29, no. 12, pp. 1809-1816, 2007.

[21] V. K. Shukla and S. Kumar, "Investigations of environmental induced effects on $\mathrm{AlQ}_{3}$ thin films by AFM phase imaging," Applied Surface Science, vol. 253, no. 16, pp. 6848-6853, 2007.

[22] V. K. Shukla and S. Kumar, "Conversion of a green light emitting zinc-quinolate complex thin film to a stable and highly packed blue emitter film," Synthetic Metals, vol. 160, no. 5-6, pp. 450454, 2010.

[23] E. Margapoti, V. Shukla, A. Valore et al., "Excimer emission in single layer electroluminescent devices based on $[\operatorname{ir}(4,5-$ diphenyl-2-methylthiazolo) ${ }_{2}$ (5-methyl-1, 10-phenanthroline) $]^{+}$ $\left[\mathrm{PF}_{6}\right]^{-}$," Journal of Physical Chemistry C, vol. 113, no. 28, pp. 12517-12522, 2009. 

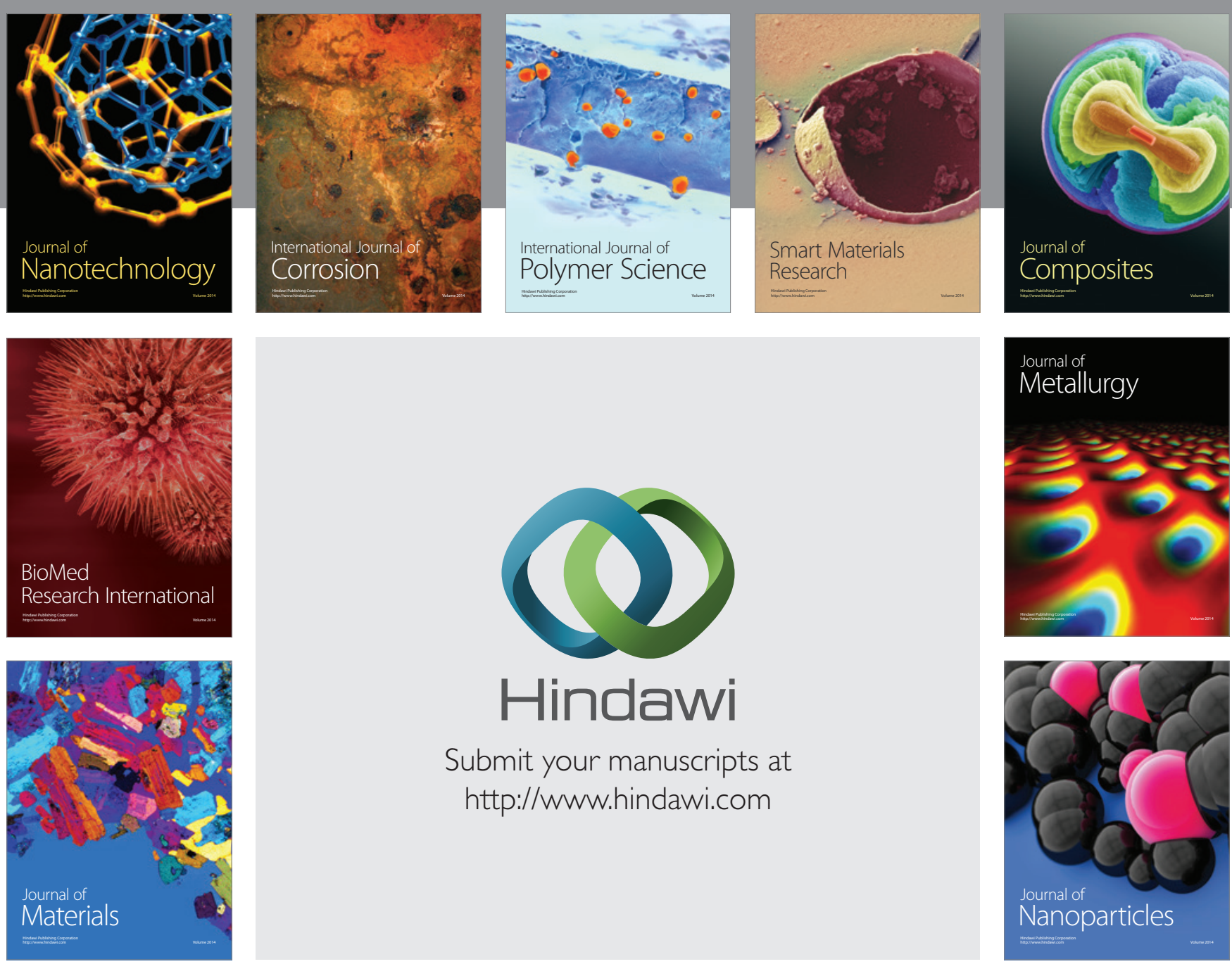

Submit your manuscripts at http://www.hindawi.com
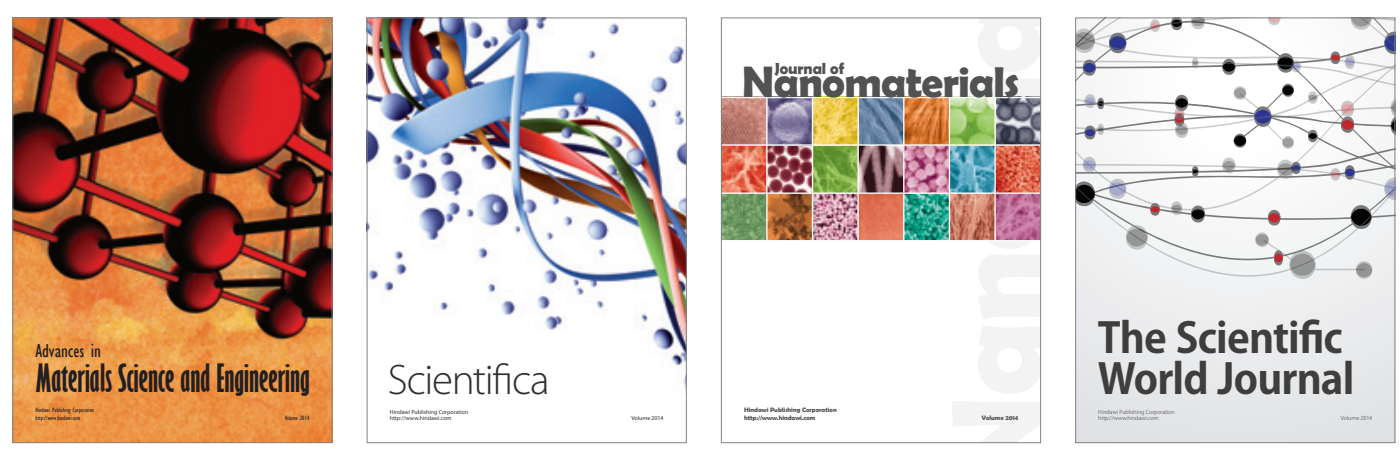

\section{The Scientific World Journal}
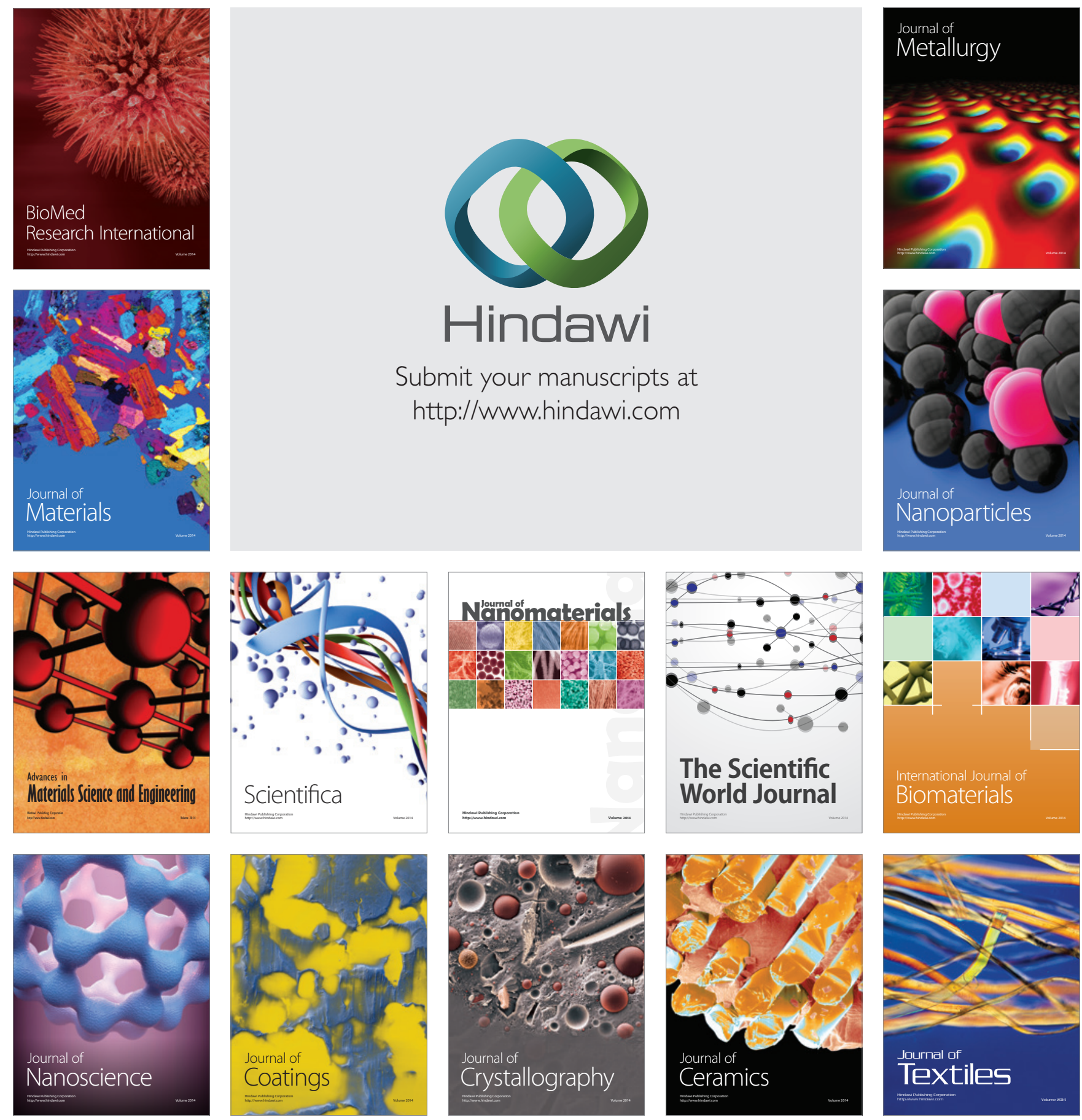